\title{
Variação fonético-fonológica no Amapá: uma proposta de análise geossociolinguística
}

Phonological-phonetic variation in Amapá: a proposal of geossociolinguistic analysis

\author{
Romário Duarte SANCHES* \\ Universidade do Estado do Amapá (UEAP) \\ Universidade Federal do Pará (UFPA)
}

RESUMO: Este estudo tem por objetivo apresentar uma proposta de análise geossociolinguística para os dados fonéticos do Projeto Atlas Linguístico do Amapá (ALAP). Como suporte teórico-metodológico têm-se as discussões sobre o modelo de geossociolinguística de Razky (2010) e os trabalhos de Razky e Guedes (2015) e Razky e Sanches (2016). O referido modelo propõe contemplar a análise da variação geográfica e social dos fenômenos linguísticos em geral. Neste sentido, a proposta de análise buscará suprir a ausência do aspecto social da variação linguística presente nas cartas fonéticas do Projeto ALAP. Como resultado, acredita-se que por meio da análise geossociolinguística é possível ter uma visão macro do fenômeno linguístico, pois além de compreender a influência de fatores linguísticos, será possível perceber se os fatores extralinguísticos (espaço geográfico, sexo e faixa etária) também exercem influência na realização ou não realização de determinados fenômenos fonéticos.

PALAVRAS-CHAVE: Geossociolinguística. Variação Linguística. Variação fonéticofonológica.

ABSTRACT: This study aims to present a proposal of geossociolinguistic analysis for the phonetic data of the Project Atlas Linguistic of Amapá (ALAP). As a theoreticalmethodological support, the discussions about Razky's geossociolinguistic model (2010) and the works of Razky and Guedes (2015) and Razky and Sanches (2016) are discussed. This model contemplates the analysis of the geographic and social variation of linguistic phenomena. In this sense, the proposed analysis will seek to overcome the absence of the social aspect of the linguistic variation present in the phonetic chart of the ALAP project. As a result, it is believed

\footnotetext{
* Professor de Linguística na Universidade do Estado do Amapá e doutorando em Letras (Linguística) pela Universidade Federal do Pará. E-mail: romario.sanches@ueap.edu.br
} 
that through the geosociolinguistic analysis it is possible to have a macro view of the linguistic phenomenon, since besides understanding the influence of linguistic factors, it will be possible to understand if the extralinguistic factors (geographic space, sex and age group) are influencing the realization or non-realization of phonetic phenomena.

KEYWORDS: Geosociolinguistic. Linguistic variation. Phonological-phonetic variation.

\section{Introdução}

O campo da Dialetologia ${ }^{1}$, acompanhado de seu método geolinguístico, tem crescido bastante no mundo ocidental, sobretudo no Brasil. Atualmente, é possível contemplar a publicação de inúmeros atlas linguísticos de diferentes dimensões, desde os microatlas (atlas locais ou estaduais) até aos macroatlas (regionais, nacionais e continentais).

Os atlas linguísticos representam um valioso acervo científico para linguística e para outras ciências interessadas, já que trazem informações cartográfico-linguísticas sobre diferentes domínios de uma língua (fonético-fonológico, semântico-lexical, morfossintático, prosódico, etc.) e o seu estágio atual (variação ou mudança linguística), podendo ser analisada de forma sincrônica e diacrônica.

A respeito dos aspectos fonéticos de uma língua natural, Aguilera (2004) defende a importância da aproximação dos estudos fonéticos com o método geolinguístico e com a descrição do Português Brasileiro. Pois, para se chegar à descrição e mapeamento de uma língua é necessário que o linguista utilize-se, necessariamente, dos estudos descritivos no nível da fonética articulatória, para que então, seja possível registrar, em forma de atlas, os fenômenos fonéticos (se for o caso) no espaço geográfico e social, mostrando sua origem e direção.

Neste contexto, o objetivo deste artigo é apresentar uma proposta de análise geossociolinguística para os aspectos fonético-fonológicos do Projeto Atlas Linguístico

\footnotetext{
1 “o ramo da Linguística que se ocupa da identificação e descrição dos diferentes usos de determinada língua, considerando a distribuição diatópica, os aspectos socioculturais e a cronologia dos dados" (CARDOSO, 2016, p. 13).
} 
do Amapá (ALAP), justificando-se pela carência de trabalhos voltados para a descrição da variação fonética e fonológica no Estado do Amapá.

$\mathrm{O}$ artigo está dividido em três partes. A priori, comenta-se sobre um dos maiores projetos geolinguísticos já firmados no Brasil, o Projeto Atlas Linguístico do Brasil (ALiB) e sua contribuição para o cenário linguístico na Região Norte. A seguir, apresenta-se o Projeto Atlas Linguístico do Amapá (ALAP) e seu estágio atual. Por último, discute-se uma proposta de análise geossociolinguística para os dados fonéticos do Projeto ALAP, na intenção de fomentar novos estudos sobre o perfil fonéticofonológico do português falado no Amapá.

\section{O Projeto ALiB e sua contribuição para a Região Norte do Brasil}

Nesta seção, apresenta-se as principais contribuições do Projeto Atlas Linguístico do Brasil (ALiB) para o cenário linguístico da Região Norte do Brasil. Deste modo, é válido ratificar que o ALiB tornou-se um dos maiores projetos já firmados no Brasil, sobretudo na área da geolinguística. O momento marcante e que deu impulso para a construção do ALiB foi o Seminário Caminhos e Perspectivas para a Geolinguística no Brasil, realizado na Universidade Federal da Bahia, em 1996. Tal evento foi favorável à construção do projeto, visto que conseguiu agregar pesquisadores do campo da Dialetologia e da Sociolinguística.

O principal objetivo do Projeto ALiB é "descrever, com base em dados empíricos, sistematicamente coletados, a realidade linguística do país (...)" (CARDOSO, 2014, p. 21). Após 20 anos de trabalho coletivo, o projeto tem seus dois primeiros volumes publicados em 2014 (vol. I. Introdução e vol. II. Cartas Linguísticas 1). O lançamento ocorreu durante o III Congresso Internacional de Dialetologia e Sociolinguística, realizado na Universidade Estadual de Londrina - UEL, em outubro de 2014. Essa publicação, por enquanto, vem evidenciando uma parcela notável da realidade linguística brasileira. Em entrevista, dada à TV universitária da Universidade Federal da Bahia (TV UFBA), Suzana Cardoso ${ }^{2}$ afirma que ainda serão necessários cerca de 20

\footnotetext{
${ }^{2}$ A professora Suzana Cardoso é a principal referência em relação aos estudos geolinguísticos no Brasil. Já que foi uma das coautoras do primeiro atlas brasileiro, Atlas Prévio dos Falares Baianos (ROSSI et al., 
volumes para que todo o material coletado pelo Projeto ALiB seja publicado. Enquanto não se desfruta dessa ampla realidade linguística brasileira, as pesquisas continuam progredindo sobre o campo de estudo.

Desde 1996 até os dias atuais, o Projeto ALiB vem contribuindo amplamente com a formação de novos pesquisadores na área da Dialetologia e da Sociolinguística, trazendo um vasto conhecimento científico sobre o Português Brasileiro, em diferentes níveis: lexical, semântico, fonológico, fonético, morfológico, sintático, discursivo, pragmático e entre outros. São inúmeros os trabalhos já desenvolvidos e que foram orientados ou coordenados pelos diretores científicos do referido projeto. Entre esses trabalhos há inúmeros atlas linguísticos, artigos científicos, teses, dissertações e monografias (PAIM, 2012; MOTA, 2015).

Atualmente, o Comitê Nacional do Projeto ALiB é composto pelos seguintes professores pesquisadores:

Diretora Presidente - Jacyra Andrade Mota (UFBA), pela Diretora Executiva - Silvana Soares Costa Ribeiro (UFBA) e pelos Diretores Científicos: Abdelhak Razky (UFPA); Aparecida Negri Isquerdo (UFMS); Conceição Maria de Araújo (UFMA); Fabiane Cristina Altino (UEL); Felício Wessling Margotti (UFSC); Marcela Moura Torres Paim (UFBA); Maria do Socorro Silva de Aragão (UFPB/UFC); Marilucia Barros de Oliveira (UFPA); Regiane Coelho Pereira Reis (UFMS); Valter Romano (UFLavras) e Vanderci de Andrade Aguilera (UEL) (OLIVEIRA; PAIM; RIBEIRO, 2018, p. 214).

Vale lembrar que o Comitê Nacional está subdivido em seis equipes regionais: Regional Pará, Regional Ceará, Regional Bahia, Regional Mato Grosso do Sul, Regional Paraná e Regional Rio Grande do Sul. No caso da Regional Pará, esta ficou sob a responsabilidade do prof. Dr. Abdelhak Razky, da Universidade Federal do Pará e Universidade de Brasília.

Sobre a contribuição do Projeto ALiB para os estudos linguísticos no Norte do Brasil, é quase impossível não mencionar as ações do grupo de pesquisa Gessociolinguística e Socioterminologia (GeoLinTerm), da Universidade Federal do Pará, coordenado pelo prof. Abdelhak Razky. O GeoLinTerm é considerado um macroprojeto de pesquisa que busca investigar problemáticas em torno do Português

1963). Também foi autora do Atlas Linguístico do Sergipe II (CARDOSO, 2005). E presidiu o Projeto Atlas Linguístico do Brasil desde 1996 até maio de 2018, ano de seu falecimento. 
Amazônico e que estejam inseridas em um dos cinco eixos de estudo: (i) o Atlas Linguístico do Brasil - Regional Norte (ALiB-Norte); (ii) o Altas Geossociolinguístico do Pará (ALiPA); (iii) os Atlas Linguísticos Regionais do Norte do Brasil (ALiN); (iv) Terminologia e Socioterminologia no Brasil (SocioTerm); e (v) Atlas Linguístico do Português falado em Áreas Indígenas (ALiPAI).

Diante dos eixos de investigação do grupo GeoLinTerm, é possível identificar que sua maioria está relacionado à área da geolinguística. Destacam-se aqui dois deles que estão inteiramente ligados ao Projeto ALiB, o eixo (i) e (iii).

O eixo (i), Atlas Linguístico do Brasil - Regional Norte (ALiB-Norte), foi iniciado em 2006, com objetivo de dinamizar e organizar as ações do Projeto ALiB, sobretudo na coleta de dados prevista nos estados da Região Norte. Neste sentido, essa ação foi fundamental para fomentar a área da linguística na Amazônia brasileira, pois contribuiu com a coleta de dados para o Projeto ALiB, além de possibilitar a produção acadêmica (em forma de artigos, monografias, dissertações e teses) de estudos científicos sobre a variação fonética, lexical e morfossintática do português falado na Região Norte, tendo por base os dados do referido projeto.

Já o eixo (iii), Atlas Linguísticos Regionais do Norte do Brasil (ALiN), surge diante da realidade geossocioliguística da região, no que diz respeito a carência de estudos descritivos e de documentação da variação linguística do português falado na Amazônia. O objetivo central foi fomentar novos estudos na área da geolinguística, principalmente na elaboração de novos atlas linguísticos para a Região Norte. Tendo em vista que até meados de 2004 o Norte possuía apenas três atlas linguísticos: o Atlas Linguístico Sonoro do Pará (ALiSPA), o Atlas Linguístico da Mesorregião do MarajóPA e o Atlas Linguístico do Amazonas (ALAM). Atualmente, os estudos relacionados ao eixo (iii) ajudaram na construção do Atlas Linguístico do Amapá (ALAP), e está auxiliando na elaboração do Atlas Linguístico de Rondônia (ALiRO).

Para além das contribuições do grupo GeoLinterm, de modo geral, é possível contemplar a construção de atlas publicados e em andamento, como: Atlas Linguístico do Amapá (ALAP), Microatlas Linguístico da área indígena Karipuna do Amapá, Atlas Linguístico do Amazonas (ALAM); Atlas dos Falares do Baixo Amazonas (AFBAM); Atlas Linguístico dos Falares do Alto Rio Negro (ALFARiN); Atlas Linguístico dos Falares de Manaus (ALFAMA); Atlas Linguístico do Sul Amazonense (ALSAM); Atlas 
Etnolinguístico do Acre (ALAC); Atlas Linguístico Sonoro do Pará (ALiSPA); Atlas Léxico Sonoro do Pará (ALeSPA); Atlas Linguístico da Mesorregião do Marajó/PA; Atlas Linguístico de Rondônia (ALiRO); Atlas Linguístico Topodinâmico e Topoestático do Estado do Tocantins (ALiTTETO), etc.

Com isso, percebe-se que, na Região Norte do Brasil, a pesquisa geolinguística ganhou um número razoável de atlas linguísticos regionais/estaduais em função do empenho e esforço de professores-pesquisadores que, de alguma forma, receberam contribuições do Projeto ALiB, seja por meio de sua formação acadêmica seja por meio do arcabouço teórico-metodológico do projeto.

\section{O Atlas Linguístico do Amapá}

No Amapá, há poucos registros de estudos publicados na área da geolinguística. No entanto, esses trabalhos vêm contribuindo para o crescimento do cenário linguístico no Estado. Um dos mais importantes, sem dúvida, é o Atlas Linguístico do Amapá, sob a autoria de Abdelhak Razky, Celeste Ribeiro e Romário Sanches, lançado em 2017, durante o V Workshop do ALAP, evento organizado pelo grupo de pesquisa ALAP.

$\mathrm{O}$ atlas traz informações linguísticas importantes, relacionados aos componentes fonéticos, fonológicos, semânticos e lexicais do português falado no Amapá. A obra está dividida da seguinte forma: 1) Estado do Amapá; 2) Os municípios de pesquisa; 3) Metodologia; 4) Cartas introdutórias; 5) Cartas Fonéticas; 6) Cartas Lexicais e 7) Cartas estratificadas.

Em relação à metodologia do Projeto ALAP foram considerados para compor sua rede de pontos, 10 localidades, dentre os 16 municípios do Estado do Amapá. A seleção foi feita mediante alguns critérios, como a densidade demográfica e populacional; os aspectos históricos, econômicos e socioculturais das localidades; além do tempo de origem de cada município.

É importante ressaltar que em decorrência da dificuldade de encontrar informantes com o perfil exigido pelo Projeto ALAP, os municípios de Serra do Navio, Ferreira Gomes, Pracuúba, Itaubal, Vitória do Jarí e Cutias não foram considerados como pontos de inquérito. As localidades selecionadas foram: (01) Macapá, (02) 
Santana, (03) Mazagão, (04) Laranjal do Jarí, (05) Pedra Branca do Amaparí, (06) Porto Grande, (07) Tartarugalzinho, (08) Amapá, (09) Calçoene e (10) Oiapoque, conforme ilustra a figura abaixo:

Figura 01 - Rede de pontos do ALAP

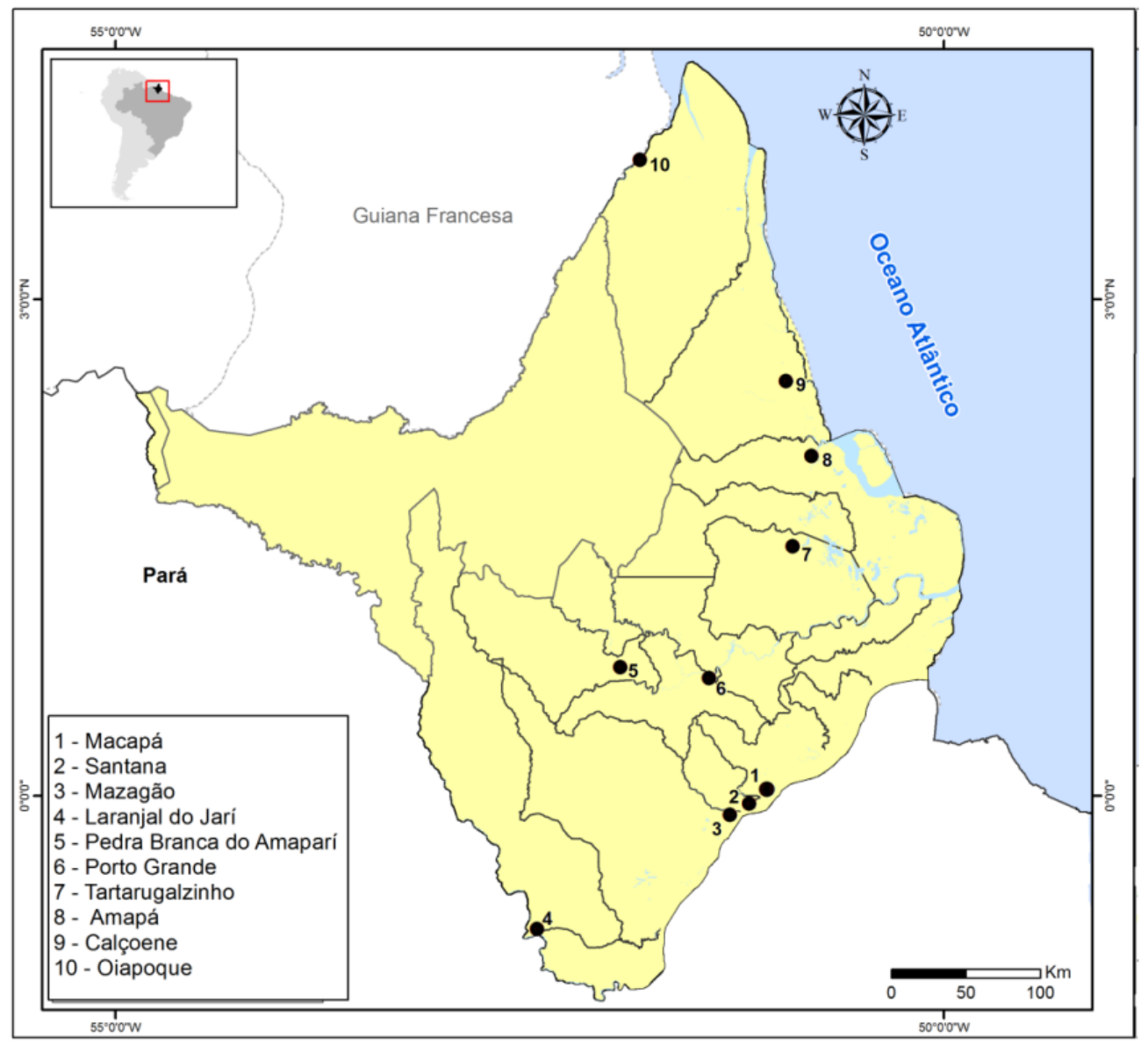

Fonte: Razky, Ribeiro e Sanches (2017, p. 53) (adaptado pelo autor).

Para a seleção dos informantes do ALAP foram considerados 40 colaboradores residentes nos respectivos pontos fixados. Em cada localidade foram entrevistados quatro informantes, com o seguinte perfil: um homem e uma mulher de 18 a 30 anos, com ensino fundamental incompleto; e um homem e uma mulher de 50 a 75 anos com ensino fundamental incompleto. Os informantes se dividem em dois grupos: sexo (homens e mulheres) e faixa etária (os de primeira faixa etária (18-30) e os de segunda faixa etária (50-75)) 
No que tange as cartas fonéticas do referido atlas, estas apresentam os fenômenos e processos fonético-fonológicos que caracterizam os falares do Amapá; já as cartas lexicais exploram as diferentes denominações para espécies de plantas, frutas, animais, etc., além das diferentes formas lexicais que nomeiam comportamentos sociais e culturais.

A partir de o lançamento do ALAP os estudos geolinguísticos no Estado concentraram-se na descrição e na análise de fenômenos lexicais, como o trabalho de Ribeiro e Sanches (2013), Silva e Sanches (2014), Sanches (2015), Razky e Sanches (2015), entre outros. No entanto, vale frisar que anterior ao ALAP foi possível identificar duas dissertações de mestrado sobre variação fonética no Amapá, ambas tendo como base o corpus do Projeto ALiB. Trata-se do estudo de Ribeiro (2008), sobre o (r) em posição pós-vocálica, e o trabalho de Fernandes (2009), sobre a lateral (lh). Em decorrência dessa carência, surge a necessidade de explorar e analisar os fenômenos fonético-fonológicos na fala de amapaenses, temática a ser discutida na seção seguinte.

\section{Uma proposta de análise geossociolinguística dos aspectos fonético- fonológicos do falar amapaense}

Como já mencionado anteriormente, o Atlas Linguístico do Amapá (RAZKY; RIBEIRO; SANCHES, 2017) apresenta a descrição e o mapeamento fonético-lexical do português falado no Estado. Entretanto, esses resultados necessitam de uma análise linguística para além da apreciação das cartas temáticas que compõe o atlas. Diante dessa problemática, foi criado em fevereiro de 2019 o projeto de pesquisa macro ${ }^{3}$ intitulado "Análise Geossociolinguística dos dados do Projeto ALAP" na intenção de fomentar novos estudos variacionistas sobre o aspecto fonético-fonológico do português falado no Amapá.

Esta proposta de análise se apoiará no modelo de geossociolinguística (RAZKY, 2010) que tem como objetivo evidenciar os fenômenos linguísticos, em seu nível geográfico e social. Em suma, esse modelo pode ser esquematizado da seguinte forma:

\footnotetext{
${ }^{3}$ Já aprovado em colegiado e em processo de análise para registro no Departamento de Pesquisa da Universidade do Estado do Amapá. O projeto é coordenado pelo Prof. Me. Romário Duarte Sanches e está vinculado ao Grupo de Pesquisa Atlas Linguístico do Amapá.
} 
Figura 02 - Modelo de análise geossociolinguística

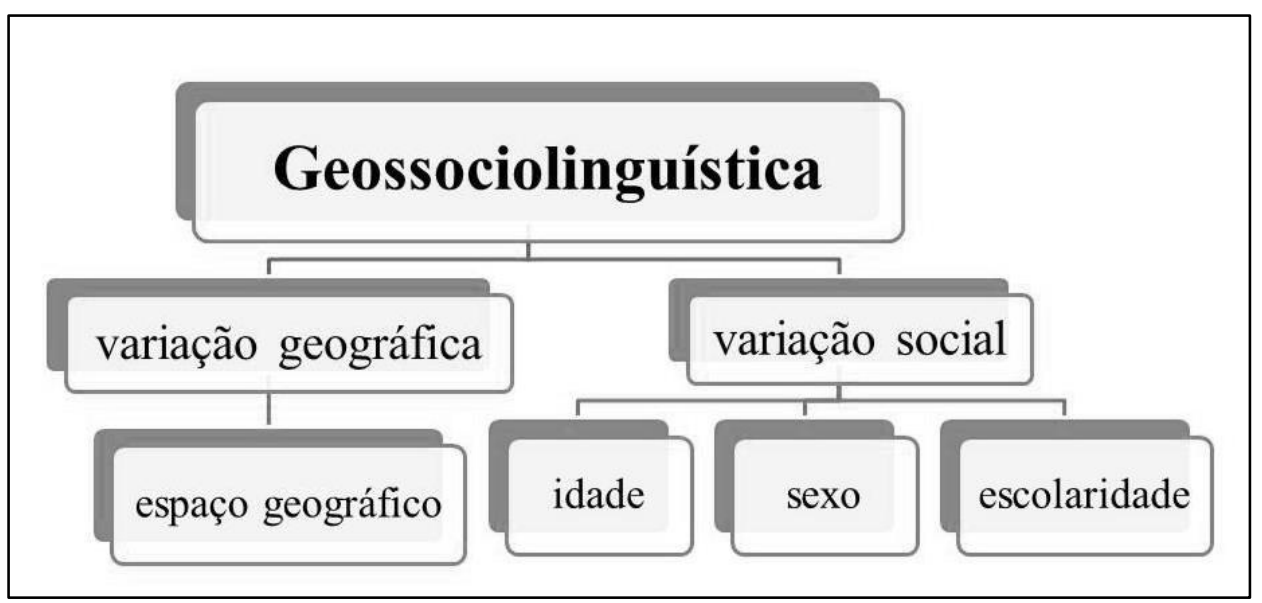

Fonte: Sanches (2019, p. 21).

De acordo com Sanches (2019), a geossociolinguística busca controlar o aspecto geográfico e social da variação linguística. Em relação ao primeiro, o foco está centrado na caracterização de áreas dialetais ou de agrupamentos léxico-fonéticos ${ }^{4}$; já o segundo, concentra-se nas influências de variáveis sociais, como idade, sexo, nível de escolaridade e etc.

Razky e Guedes (2015) acreditam que esse controle social dos dados linguísticos contribui de forma elementar para o mapeamento geossociolinguístico. Em consonância, Razky e Sanches (2016) comentam a possibilidade de analisar esses mapas linguísticos sob uma perspectiva geossocial, isto é, uma análise que contemple o espaço geográfico (variação geográfica ou diatópica) e os fatores sociais (variação diassexual, diageracional e diastrática).

Com base na contribuição que o modelo geossociolinguístico oferece para análise linguística, propõe-se então investigar as cartas fonéticas do Projeto ALAP, buscando entender a variação geográfica e social dos fenômenos fonéticos, e como

\footnotetext{
${ }^{4}$ Coexistência de variantes linguísticas em uma mesma demarcação territorial (RAZKY, 2013). 
essas variáveis linguísticas e extralinguísticas influenciam o português falado no Amapá.

Para isto, a execução do projeto "Análise Geossociolinguística dos dados do ALAP" se dará por meio de três etapas: $1^{a}$ ) a formação de novos pesquisadores na área da Sociolinguística e da Dialetologia; $2^{\mathrm{a}}$ ) o tratamento e a organização dos dados fonéticos; $3^{\mathrm{a}}$ ) a produção, a divulgação e a publicação dos resultados.

A primeira etapa, em execução, conta com a colaboração voluntária de oito estudantes do curso de Letras da Universidade do Estado do Amapá. A cada quinze dias do mês, o grupo reúne-se para formação em pesquisa variacionista, isto é, são realizadas discussões teóricas e metodológicas sobre a referida área, bem como a socialização de estudos já realizados sobre fenômenos fonéticos específicos.

Já na segunda etapa, busca-se dividir tarefas entre os membros do projeto, os quais ficarão responsáveis pela organização, tratamento e análise de dois fenômenos fonéticos cartografados para o ALAP. Os fenômenos que serão analisados correspondem a uma carta fonética, como mostra o quadro a seguir.

Quadro 01 - Fenômenos fonéticos do ALAP

\begin{tabular}{|l|l|}
\hline$N^{\mathbf{N}}$ & FENÔMENOS FONÉTICOS \\
\hline CARTAF01 & Vogal média pretônica posterior /o/ \\
\hline CARTAF02 & Vogal média pretônica anterior /e/ \\
\hline CARTAF03 & Realização do /l/ em [r] \\
\hline CARTAF04 & Realização do grupo (nd) \\
\hline CARTAF05 & /R/ em coda silábica em posição interna realização glotal \\
\hline CARTAF06 & /S/ em coda silábica em posição interna realização palatal \\
\hline CARTAF07 & /S/ em coda silábica em posição externa realização palatal \\
\hline CARTAF08 & Ditongo /ei/ manutenção do ditongo \\
\hline CARTAF09 & Ditongo /ai/ manutenção diante de [S] \\
\hline CARTAF10 & Ditongo /ou/ manutenção do ditongo \\
\hline CARTAF11 & Ditongação de vogais diante de /s/ \\
\hline CARTAF12 & Palatalização de /d/ diante de /i/ e /e/ \\
\hline CARTAF13 & Palatalização de /t/ diante de /i/ e /e/ \\
\hline CARTAF14 & Nasalização de vogais de /m/ e /n/ \\
\hline CARTAF15 & Palatalização de (nh) \\
\hline CARTAF16 & Alteamento de vogal média anterior /e/ em contexto final \\
\hline
\end{tabular}

Sobre a última etapa, busca-se auxiliar os membros da equipe a produzirem textos acadêmicos, sobretudo, no que se refere à elaboração de artigos científicos para divulgação e publicação dos resultados alcançados. 
Para elucidar como funcionará a análise geossociolinguística dos dados fonéticos do ALAP, apresentam-se a seguir as cartas fonéticas F08 e F10, respectivamente sobre o ditongo [ej] e [ow].

Figura 03 - Variação diatópica do ditongo /ei/

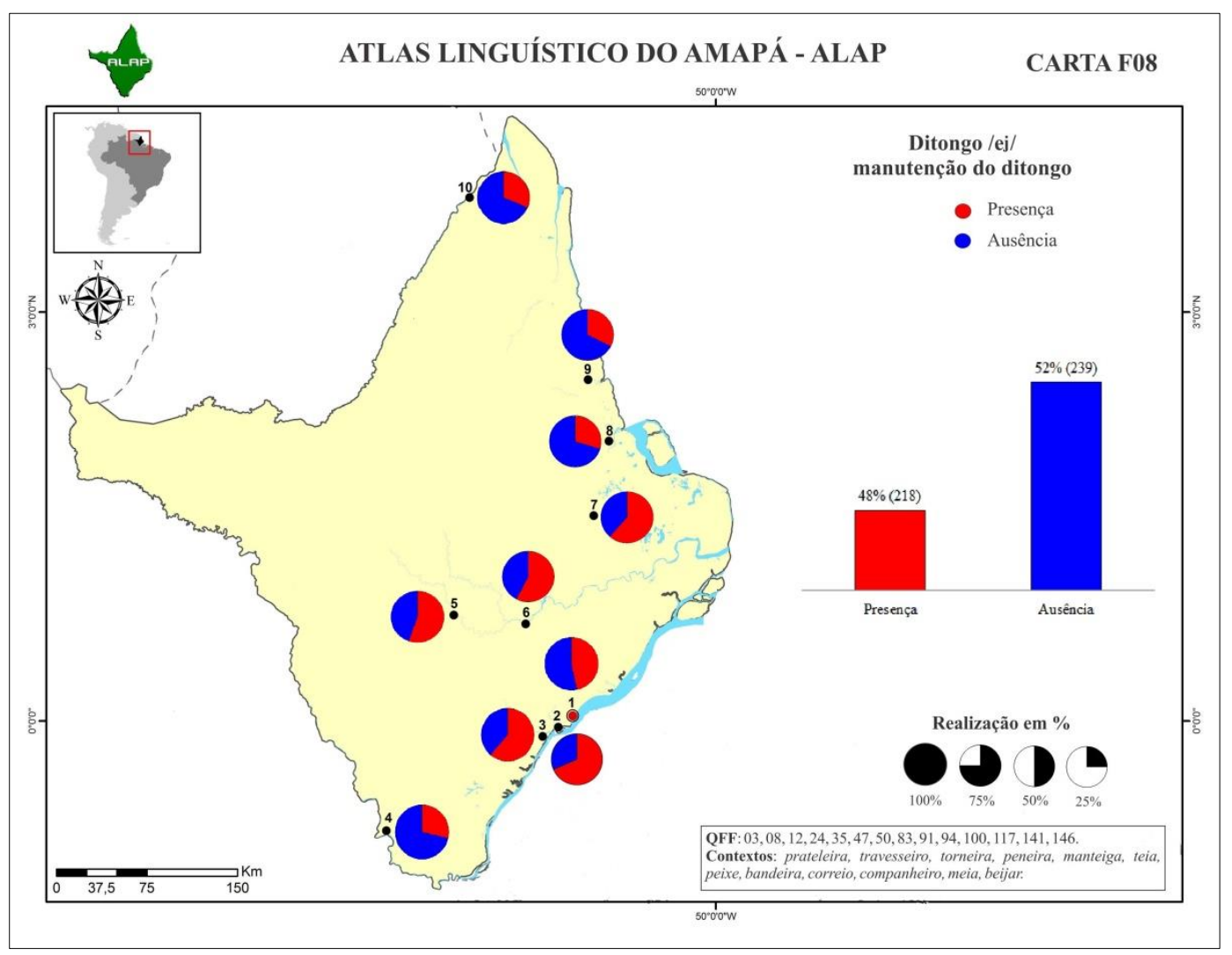

Fonte: Razky, Ribeiro e Sanches (2017, p. 63) (adaptado pelo autor).

Na figura 03, observa-se a configuração da variação diatópica em relação à presença e à ausência do ditongo /ei/ em vocábulos como: prateleira, travesseiro, torneira, peneira, manteiga, teia, peixe, bandeira, correio, companheiro, meia e beijar. Assim, os resultados gerais mostram que $48 \%$ dos entrevistados tendem a realizar o ditongo [ej] e 52\% não realizam o referido ditongo, ou seja, tende a apagar a semivogal, como em pratele $[\varnothing] \mathrm{ra}$, travesse $[\varnothing] \mathrm{ro}$, torne $[\varnothing] \mathrm{ra}$, e assim por diante. Ainda sobre a 
variação diatópica, constatou-se que o fator geográfico das localidades pesquisadas não está condicionando a realização ou não realização do ditongo [ej].

Figura 04 - Variação diatópica do ditongo /ou/

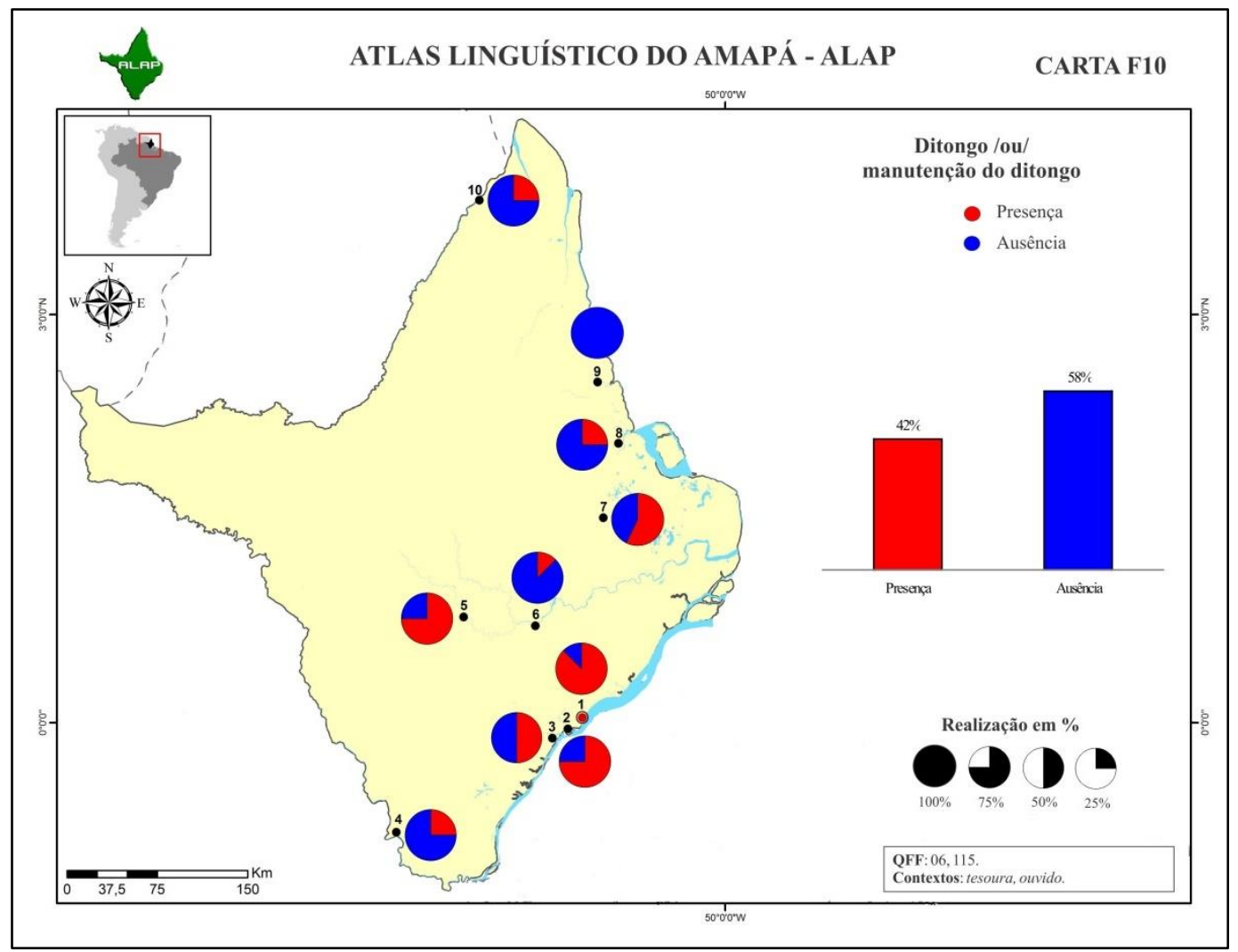

Fonte: Razky, Ribeiro e Sanches (2017, p. 65).

$\mathrm{Na}$ figura 04, apresenta-se a presença e a ausência do ditongo [ow] nos vocábulos tesoura e ouvido. A configuração diatópica desse fenômeno é diferente da que foi apresentada na figura 03, uma vez que os resultados gerais da figura 04 mostram que $42 \%$ dos dados tendem a manter o ditongo [ow] e $58 \%$ tendem a apagar. Neste caso, o uso recorrente é teso[Ø]ra e o[Ø]vido. Em uma análise do espaço geográfico, fica perceptível que nos pontos 04 (Laranjal do Jarí), 06 (Porto Grande), 08 (Amapá), 09 (Calçoene) e 10 (Oiapoque) os informantes entrevistados tendem a apagar o ditongo [ow], já nos pontos 01 (Macapá), 02 (Santana), 05 (Pedra Branca do Amaparí) e 07 (Tartarugalzinho) tendem a manter o referido ditongo.

Diante da figura 03 e 04, é possível analisar a variação geográfica, entretanto, é inviável identificar qual o perfil social dos informantes, tendo em vista que o ALAP não 
contemplou em seu mapeamento a estratificação social dos dados fonéticos. Daí a necessidade de analisar os fatores sociais, como sexo e idade, para então identificar se há influência dessas variáveis no uso dos ditongos e de outros fenômenos fonéticofonológicos falados no Amapá.

\section{Considerações finais}

Acredita-se que a abordagem geossociolinguística aplicada aos dados de fala do projeto ALAP fornecerá uma visão macro dos fenômenos fonético-fonológicos investigados, auxiliando a responder perguntas como: quem tende a manter ou a apagar os ditongos pesquisados? Homens ou mulheres? Jovens ou idosos? Ou será que não há influência dessas variáveis? As respostas a estas perguntas poderão ser sanadas a partir de uma análise de base geossociolinguística e comparativa com outros atlas linguísticos já publicados, verificando como se comportam as variáveis sexo e faixa etária, de acordo com cada fenômeno fonético mapeado.

Deste modo, será possível verificar o comportamento linguístico e extralinguístico dos fenômenos fonético-fonológicos presentes na fala de amapaenses, como a realização das vogais médias pretônicas, o processo de rotacismo $(1>\mathrm{r})$, do gerúndio (nd), do /R/ em coda silábica, do /S/ em coda silábica, dos ditongos, do fenômeno de palatalização, de nasalização, o alteamento das vogais médias e entre outros.

A publicação desses resultados poderá fornecer novos indícios sobre o português falado no Amapá ou poderá convergir com os resultados já evidenciados em outros atlas linguísticos do Norte do Brasil e outras regiões. Espera-se em breve poder compartilhar com a sociedade em geral as análises dos aspectos fonético-fonológicos do falar amapaense.

\section{REFERÊNCIAS}

AGUILERA, V. de A. A importância dos estudos fonéticos na geolinguística para a descrição do Português do Brasil. SIGNUM: Estud. Ling., Londrina, n. 7/1, p. 9-19, jun. 2004. 
CARDOSO, S. A história do Atlas Linguístico do Brasil. In: CARDOSO, S. (et al.). Atlas Linguístico do Brasil: introdução. Londrina: EDUEL, 2014.

CARDOSO, S. Atlas Linguístico de Sergipe II. Salvador: EUFBA, 2005.

CARDOSO, S. Dialetologia. In: MOLliCA, M. C.; FERRAREZI JR., C. Sociolinguística, sociolinguísticas: uma introdução. São Paulo: Contexto, 2016. p. 1322.

FERNANDES, M. E. P. Distribuição Geo-sociolinguística da Lateral Palatal /lh/nos estados do Amapá e Pará. Dissertação (Mestrado em Letras: Linguística e Teoria Literária) - Universidade Federal do Pará, 2009.

MOTA, J. A. Análises do corpus do Projeto Atlas Linguístico do Brasil (ALiB): balanço do estágio atual. In: MOTA, J. A (et al.). Documentos 5: projeto Atlas Linguístico do Brasil, avaliação e perspectivas. Salvador: Quarteto, 2015, p. 23-70.

OLIVEIRA, J. M. de; PAIM, M. M. T.; RIBEIRO, S. S. C. A importância do Atlas linguístico do Brasil para o ensino de português. Revista Tabuleiro de Letras (PPGEL, Salvador, online), vol.: 12; n. 03, dezembro, p. 212-221, 2018.

PAIM, M. M. T. A presença do projeto ALiB nos estudos sobre a língua portuguesa. In: CARDOSO, S. (et al.). Documentos 3: projeto atlas linguístico do Brasil. Salvador: Vento Leste, 2012, p. 33-76.

RAZKY, A.; GUEDES, R. Le continuum des regroupements lexicaux dans l'atlas géosociolinguistique du Pará. Revista Géoliguistique. Centre de Dialectologie. GIPSAlab - Univ. Grenoble Alpes. n. 15, 2015.

RAZKY, A.; SANCHES, R. Variação geossocial do item lexical riacho/córrego nas capitais brasileiras. Gragoatá, Niterói, n.40, p. 70-89, 2016.

RAZKY, A. Pour une approche géo-sociolinguistique de la variation phonétique. Lenguaje (Universidad del Valle), v. 32, p. 313-330, 2010.

RAZKY, A. A dimensão sociodialetal do léxico no Projeto Atlas Linguístico do Brasil. SIGNUM: estudos linguísticos, Londrina, n. 16/2, p. 247-270, 2013.

RAZKY, A.; RIBEIRO, C. M. da R.; SANCHES, R. Atlas Linguístico do Amapá. São Paulo: Labrador, 2017.

RIBEIRO, C. M. da R. A variável (r) posvocálica medial nos estados do Amapá e Pará: um estudo Geossociolinguístico. Dissertação (Mestrado em Letras: Linguística e Teoria Literária) - Universidade Federal do Pará, 2008.

ROSSI, N. (et al.). Atlas Prévio dos Falares Baianos. Ministério da Educação e Cultura/Instituto Nacional do Livro: Rio de Janeiro, 1963. 
SANCHES, R. D. Gambá ou mucura? Como falam os amapaenses. In: RAZKY, Abdelhak (et al.). Anais do VII SERGEL - VII Seminário Regional de Geossociolinguística / Belém: UFPA/Faculdade de Letras, p. 19-28, 2019. SANCHES, R. Variação Lexical nos dados do Projeto Atlas Geossociolinguístico do Amapá. (Dissertação de Mestrado). Programa de Pós-Graduação em Letras, 2015.

SANCHES, R.; RAZKY, A. Variação lexical para o item 'prostituta' no Amapá. Revista do GELNE (UFC). , v.17, p.77 - 91, 2015.

SANCHES, R.; RAZKY, A. Variação Linguística para Cigarro de Palha e Toco de Cigarro no Atlas Linguístico do Amapá. Revista Todas as Letras (MACKENZIEOnline), v.17, p.196 - 206, 2015.

SANCHES, R.; RIBEIRO, C. M. da R. Variação lexical para libélula no Atlas Linguístico do Amapá. Web-Revista SOCIODIALETO. v.4, p.435-449, 2013.

SANCHES, R.; SILVA, M. do P. S. C. da. Variação semântico-lexical no Amapá. Linguística (Rio de Janeiro). , v.10, p.299 - 315, 2014.

TV UFBA especial. Atlas Linguístico do Brasil. Disponível em: https://www.youtube.com/watch?v=H5thheru5U4. Acesso em: 29 de nov. 2017. 